
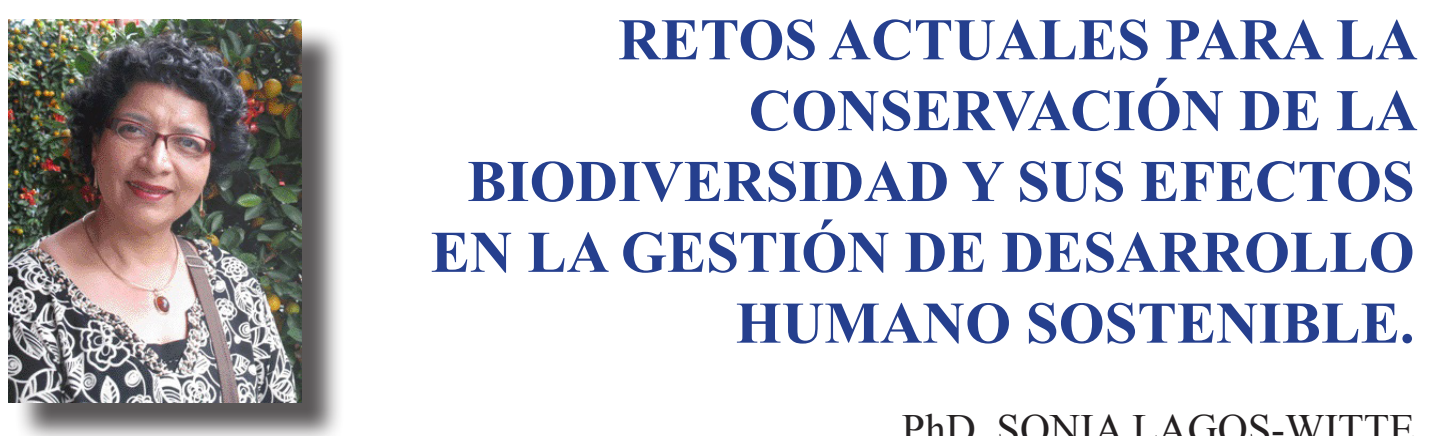

PhD. SONIA LAGOS-WITTE slagos09@gmail.com

Profesora del Doctorado en Ciencias del Desarrollo Humano de la Universidad Nacional Autonoma de Honduras ORCID:0000-0003-2874-8320

DOI: $10.5377 /$ rpdd.v6i1.12437

Recibido: agosto, 2021

Aceptado: septiembre, 2021

\title{
Una mirada regional de la biodiversidad
}

$\mathrm{D}$ aremos una breve mirada a la problemática actual, en torno a la crisis ambiental y del desarrollo humano, en el contexto global y local. En la actualidad los problemas ambientales han alcanzado y son considerados en una dimensión global, pero si utilizamos una lupa a nivel local cada problema está posicionado y tiene sus particularidades, su especificidad, representando un reto para cada sitio donde se genera.

En el documento Perspectiva Mundial sobre la Diversidad Biológica 5 (2020) de la Organización de las Nacionales Unidas (ONU) retoman con mucha preocupación ese panorama sombrío por la situación que vivimos a nivel de planeta, el Secretario general de la $\mathrm{ONU}$, Antonio Guterres, presenta este informe con su primera reflexión diciendo:

"Los traumáticos efectos de la pandemia de COVID 19 encierran importantes enseñanzas acerca de nuestra respuesta ante la crisis de la diversidad biológica. Por un lado, revelan de manera impactante la relación entre nuestra forma de tratar el mundo vivo y la aparición de enfermedades humanas. Por otro lado, la respuesta de los gobiernos y la gente en todo el mundo ha demostrado la capacidad de la sociedad para tomar medidas que antes eran inimaginables, con enormes transformaciones, muestras de solidaridad y esfuerzos multilaterales para hacer frente a una urgente amenaza común". 
El mundo necesita respuestas y aunque algunas veces parezca que nos son muy claras, se está trabajando por alcanzar estadios ambientales sostenibles. No podemos pretender el bienestar sin analizar los grandes problemas que aquejan la humanidad con ello buscar una salida que debe ser viable para todos. Tenemos la necesidad de restaurar los ecosistemas de la que depende toda la actividad humana y la urgencia de reducir los impactos negativos de dicha actividad.

En este momento de evaluación previa a la pandemia, se prevé que los objetivos del Convenio la Diversidad Biológica (CDB) y las metas Aichi no se puedan alcanzar y posiblemente se deba abordar una nueva agenda para retomar las cuestiones de fondo y así re-direccionar las políticas propuestas.

Por su parte la CEPAL, propone ocho sectores para el gran impulso a la sostenibilidad, una recuperación transformadora con igualdad y sostenibilidad. Estos ocho sectores propuestos promueven un cambio técnico, generan empleos y reducen la restricción externa y la huella digital:

1.La transición energética hacia fuentes renovables.

2.Movilidad sostenible en ciudades.

3.La revolución digital inclusiva.

4.La industria manufacturera de la salud.

5.La bioeconomía, recursos biológicos y ecosistemas naturales.

6.Valorizar y expandir la economía del cuidado.

7.La economía circular.

8.El turismo sostenible.

La agenda 2030 de los Objetivos del Desarrollo Sostenible están en una situación critica de poder ser alcanzables al 2030, pero el replanteamiento podría ser una oportunidad para un cambio de perspectiva y hasta un cambio de paradigma. No debemos negarnos a estos cambios que nos plantea esta nueva era, la resistencia al cambio traería consigo el mismo uso de prácticas convencionales que asfixian el planeta.

El administrador del PNUD Achim Steiner sostiene que "la biodiversidad desempeña un papel importante en a la reducción del riesgo del desastre, aumentando la resistencia ecológica y resiliencia de las comunidades, tenemos la necesidad de enfocarnos en medidas que puedan generar una posibilidad de sobrevivencia dentro de todos los problemas graves que tenemos como: conversión de hábitats, cambio del uso de suelos, perdida de la diversidad biológica y cultural, el impacto del cambio climático, el endeudamiento y pobreza, la crisis sanitaria crónica, impunidad, 


\section{RETOS ACTUALES PARA LA CONSERVACIÓN DE LA BIODIVERSIDAD Y SUS EFECTOS}

EN LA GESTIÓN DE DESARROLLO HUMANO SOSTENIBLE

corrupción, crimen organizado y migración forzada entre otros". Muchos de los problemas mencionados por Steiner están ejerciendo presión constante a dar paso al surgimiento de una mejor calidad de vida basado en el Desarrollo Humano Sostenible. El mundo se compone por sociedades extremadamente consumistas, los países llamados desarrollados tienen el acceso a los medios que son limitantes a las sociedades llamadas subdesarrolladas, muchas de estas últimas mantienen los niveles altos de biodiversidad. Pero para más consumo hay que demandar más de la biodiversidad, por lo tanto, la presión sobre estos recursos aumenta, impactando sobre la diversidad, no solo biológica, sino cultural.

En el informe Planeta Vivo del 2020 de WWF se expone que hemos dañado a nuestro planeta dejando pequeñas representaciones aun silvestres o prístinas. Hemos transformado aceleradamente los paisajes naturales a paisajes extensivos de producción. Podemos ver como en la amazonia se han dado estas transformaciones donde la soya está siendo uno de los cultivos prioritarios que se verán en esas tierras, antes fuentes de biodiversidad. América Latina y el Caribe ha tenido la mayor pérdida de biodiversidad de hasta el $94 \%$ de especies silvestres, siendo impactados grandemente los anfibios y los arrecifes coralinos.

La portada del Informe sobre Desarrollo Humano 2020, presenta la compleja conexión entre las personas y el planeta, representando esta interdependencia un sello distintivo del antropoceno. Esta interconexión de la naturaleza, ya la explicaba Alexander Humboldt en su ensayo Cosmos, esta relación no es nueva pues se da desde la misma aparición del hombre. Podríamos continuar con las mismas decisiones actuales o tomar una nueva dirección en cuanto a políticas públicas que son las que inciden en los componentes del Desarrollo Humano Sostenible. Entre los planteamientos del Informe IDH propone, replantear el desarrollo Humano para el antropoceno, impulsar mecanismos de cambio para impulsar la acción y explorar nuevos parámetros.

Pero como revertimos la pérdida de biodiversidad, cual es la orientación para trabajos futuros hacia el 2050. Entre algunas acciones mundiales que surgen son: la reducción del consumo, la producción sostenible, reducción de sobre explotación, contaminación e invasión de especies, acción contra el cambio climático y la conservación y, restauración, entro otras.

"Se necesita con urgencia un profundo cambio cultural y sistémico, que hasta ahora nuestra civilización no ha conseguido alcanzar: la transición a una sociedad y 
un sistema económico que valórela naturaleza. Debemos reequilibrar nuestra relación con el planeta para preservar la asombrosa diversidad de vida en la tierra y permitir una sociedad justa, saludable y próspera para finalmente asegurar nuestra propia sobrevivencia" (Informe WWF: Planeta Vivo 2020).

\section{Situación de la biodiversidad de Honduras}

Honduras se encuentra en una encrucijada por el aumento de la vulnerabilidad social y ambiental, agudizada por la crisis sanitaria de la COVID 19, la cual se viene acarreando desde hace mucho tiempo. La crisis sanitaria crónica no es solamente por el COVID 19, estaba ya profundizada desde mucho antes. Esto lo podemos ver con las estadísticas del 2019 con la problemática del dengue en Honduras, lo que nos da una buena radiografía de la situación de la crisis sanitaria. Cuando un país invierte más en armamento y en uniformes militares que en los problemas de salud del pueblo, algo no está o estará bien.

La visión de Desarrollo Humano Sostenible propone tres variables conjugables en su alcance: soportable en lo ecológico, viable en lo económico y equitativo en lo social. Honduras cuenta con una serie de instrumentos que teóricamente se ha generado, una planificación a largo plazo y hasta una visión de país. Sin embargo, parece que día a día nos aceleramos más hacia la destrucción ambiental, cuando lo que debía ocurrir es una disminución de todas aquellas acciones que son adversas al ambiente. Pero entonces ¿qué hace falta?

En el objetivo 3 de Plan de Nación 2010-2038 proclama "Una Honduras productiva generadora de oportunidades y empleo, que aprovecha de manera sostenible sus recursos y reduce la vulnerabilidad ambiental, que genera empleo y es prospera. Un enfoque basado en el ser humano, en el respeto a las costumbres y cultura de los pueblos indígenas, un desarrollo sostenible basado en armonía con la naturaleza". Con propuestas como estas podríamos pensar que como país tendríamos mejores opciones que las actuales, propuestas muy cercanas al objetivo ideal.

Honduras esta entre los veinte países alrededor del mundo más vulnerables, asediado por las tormentas, huracanes e impactos meteorológicos. Podemos registrar que estas catástrofes climáticas han afectado por décadas la economía del país y presenta un costo elevado para la reactivación socioeconómica de la sociedad. Aun podemos recordar en los setentas el huracán Fifí, el Mitch en los noventa y así otros eventos climáticos que han dejado catástrofes a su paso, en el 2020 el huracán Eta e Iota. 


\section{RETOS ACTUALES PARA LA CONSERVACIÓN DE LA BIODIVERSIDAD Y SUS EFECTOS EN LA GESTIÓN DE DESARROLLO HUMANO SOSTENIBLE}

En el informe estadístico del Instituto de Conservación Forestal de 2019 podemos apreciar los cambios que han existido en la cobertura forestal. Año con año la deforestación se proyecta con mayores valores. También muestra que mucho de los cambios del uso de suelos se da en las áreas protegidas donde esta acción según la legislación nacional es prohibitiva. Honduras es un país eminentemente forestal, que necesita políticas de restauración agresiva y masiva, con impacto local, para poder frenar este deterioro ambiental. En este contexto podemos ver como Costa Rica recuperó mucho de su bosque seco del pacifico, ejemplo digno de replicar en Honduras.

Honduras posee un Plan de Manejo Forestal con una gran posibilidad de poder manejar estas áreas con forestaría comunitaria como una alternativa de participación sostenible. Sin embargo, alarma la cantidad de planes de manejo aprobados para la explotación comercial, especialmente concesiones privadas. Mucha de la madera que va al caribe son maderas preciosas especialmente caoba y cedro, la cual no es regulada correctamente. Sin embargo una alternativa podría ser el aprovechamiento de estos bosques en proyectos de captura de carbono, oportunidad que hasta ahora ha sido limitada.

Otro instrumento desarrollado actualmente es la Estrategia Nacional de Biodiversidad con un Plan de Acción 2018 al 2022, que se alinea con el alcance de los objetivos de desarrollo sostenible. Ello podría ser una oportunidad para poner sobre la mesa de discusión esta problemática planteada e integrar a la sociedad en un proceso de gobernanza genuino.

Por otro lado, la Ley de Biodiversidad de Honduras parece estar en demora, es un compromiso de Estado asumido en el marco de convenios internacionales y regionales, que surge de la necesidad de llenar vacíos alrededor del deterioro de la biodiversidad nacional, en donde cada día las presiones humanas y los cambios ambientales merman los recursos vivos del país. Este anteproyecto de ley está en proceso de socialización y discusión, demandando su pronta aprobación e implementación.

Honduras presenta grandes problemas para los ambientalistas, pues es considerado como uno de los países más peligrosos para los defensores del medio ambiente y la tierra. Caso insigne es el de Berta Cáceres quien, por la defensa de las fuentes de agua en el occidente de Honduras y la oposición a la privatización 
de los Recursos Naturales, fue asesinada. Siendo así que, Amnistía Internacional y Global Witness ha encendido alarma ante la situación que pasa en el país haciéndolo del conocimiento público. Esta indiferencia ante esta situación se constata cuando Honduras no ha firmado el acuerdo de Escazú que entró en vigencia el 22 de abril del 2021, siendo un instrumento importante que entre otras cosas compromete al país firmante a proteger la integridad de los ambientalistas. La representante de la ONU para los Derechos Humanos afirmó "que el acuerdo de Escazú es único en su tipo y garantiza el derecho a participar en las decisiones, acceder a la información y a la justicia en materia ambiental, y a la protección de las personas defensoras".

Defender la naturaleza es sinónimo de peligro de la vida, no solo en Honduras, sino en el mundo entero. Para superar esta situación debemos escuchar las voces de los pueblos indígenas y respetarlas, así como respetar el derecho a la consulta previa, libre e informada de las comunidades, romper con la impunidad de las muertes de ambientalistas y garantizar la participación ciudadana en temas del territorio y ambiente.

Una zona en Honduras que siempre ha llamado la atención por su riqueza cultural y biológica es la Moskitia, conocida por sus características inhóspitas y su difícil acceso, que se hacía ver lejos del contexto político del país. Sin embargo, con el tiempo, esta zona es conocida por ser tierra de nadie, tierra sin leyes en donde reina la inseguridad y el tráfico de drogas, sitio que es parte del patrimonio mundial de la humanidad por estar registrado en el programa MaB de la UNESCO. Recientemente, ha llamado a la atención la apertura de carreteras que atraviesan las áreas protegidas y abren un espacio inmisericorde a la explotación agropecuaria.

En términos económicos los organismos internacionales están generando propuestas para la recuperación post COVID-1. La CEPAL presentó los desafíos de desarrollo y futuro de la cooperación internacional, este como un rompecabezas con nuevas perspectivas y nuevos paradigmas. Los niveles de consumo deben de tomar rutas diferentes en aras de lograr la equidad o la justicia social. América Latina y el Caribe es la región en desarrollo en la que la COVID-19 ha tenido el mayor impacto. Manifiesta Inger Andersen, Directora Ejecutiva de la ONU para el Medio Ambiente: "Sabemos que tiene que hacerse, qué funciona y cómo podemos alcanzar buenos resultados. Si construimos sobre lo que ya se ha logrado y ponemos a la biodiversidad en el centro de todas las políticas y decisiones - incluso en los paquetes de recuperación tras el Covid-19- podremos asegurar un mejor futuro para nuestras sociedades y el planeta". 


\section{RETOS ACTUALES PARA LA CONSERVACIÓN DE LA BIODIVERSIDAD Y SUS EFECTOS EN LA GESTIÓN DE DESARROLLO HUMANO SOSTENIBLE}

En este miso contexto el Instituto para el Medio Ambiente y el Desarrollo manifestó que entre los países con mayor prioridad para para el intercambio de deuda por programas climáticos figuraba Honduras. Sin embargo, queda una duda latente, si esta prioridad será suficiente para depositar en Honduras la confianza de la administración fondos ambientales y si técnicamente estarán preparados para el abordaje de este tema.

Las universidades tienen un papel muy importante en proceso de generación de conocimiento ambiental, con elementos y variables importantes en la generación de políticas públicas. Cuando las comunidades deciden como alcanzan sus propios objetivos y cuando los gobiernos locales caminan por la autogestión, el aprendizaje es ganancia y los proyectos dan resultados perdurables.

\section{CONCLUSIONES}

La conservación de la biodiversidad está íntimamente conectada con el bienestar humano y es parte indivisible del Desarrollo Humano Sostenible. Por lo tanto, la búsqueda de la preservación de la biodiversidad debe ser en sí la búsqueda de la preservación de la especie humana, la desaparición de una desencadenará la desaparición de la otra.

El problema territorial es un reto que debe ser regularizado por medio de políticas públicas. Estas deben ser generadas por medio de la participación en contextos de la transparencia y la gobernabilidad, garantizando la participación genuina de las poblaciones locales y los diferentes actores que se benefician del territorio.

Los recursos Naturales (flora, fauna, microorganismos) forman parte de los valores culturales de los pueblos ancestrales. Derecho que se ampara en diferentes tratados internacionales que los países han acatado y forman parte del derecho positivo. Por ello, debe respetarse ese derecho consuetudinario que fortalece la cultura de los pueblos ancestrales y aumenta el conocimiento universal.

Los pueblos y los recursos naturales del más alto interés y valor, se encuentran en su mayoría, localizados en territorios sagrados y de gran riqueza biológica. Por lo tanto, ese reconocimiento etno-ecológico y el aporte de los pueblos a la preservación de los componentes bióticos y abióticos con sus interacciones, garantizaron la existencia 
de ellos. Esta convivencia se vuelve insostenible por las presiones mercantilistas a las que estamos siendo sometidos, que abre brechas y ubica dueños de los recursos naturales que pertenecen a la humanidad.

La mayor riqueza de diversidad biológica se encuentra en espacios de formación y conocimiento cultural que se aprenden y respetan mediante prácticas culturales y procesos de formación social tradicional/ancestral.

La consulta previa, la concertación y el respeto a los territorios de uso extenso, deben ser involucrados en las políticas públicas, las políticas de investigación para la conservación, en las cadenas productivas y de comercialización (protocolo de Nagoya, Acuerdo de Escazú).

Es una necesidad continuar pensando y actuando en la armonización de las ciencias sociales y naturales...La crisis que estamos pasando nos obliga a repensar nuestro mundo y la condición humana.

Registro de Foro elaborado por Juan Pablo Suazo. 